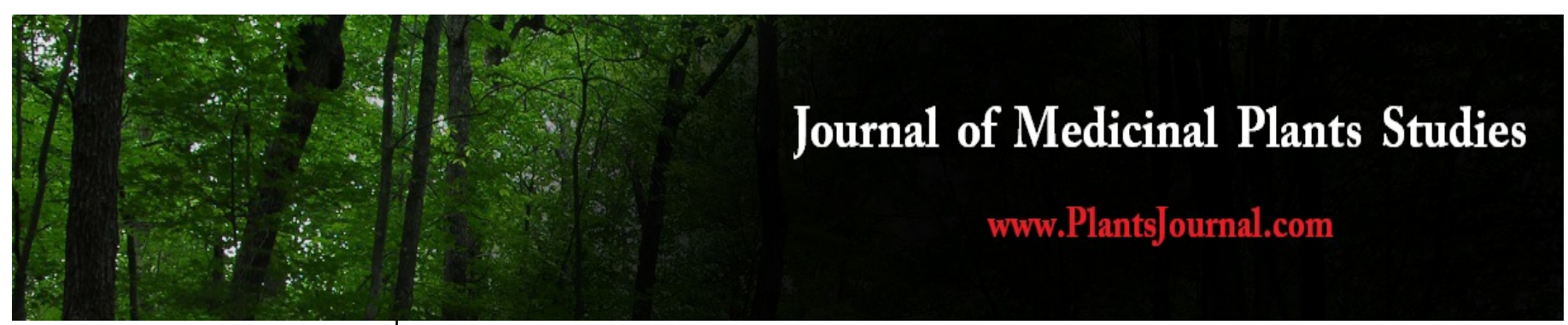

ISSN (E): 2320-3862

ISSN (P): 2394-0530

NAAS Rating: 3.53

www.plantsjournal.com

JMPS 2020; 8(6): 06-09

(C) 2020 JMPS

Received: 04-09-2020

Accepted: 09-10-2020

Sindhuja Sirigeri

DOS in Environmental Science,

University of Mysore, Mysuru,

Karnataka, India

Belagali SL

DOS in Environmental Science,

University of Mysore, Mysuru,

Karnataka, India
Corresponding Author: Sindhuja Sirigeri

DOS in Environmental Science,

University of Mysore, Mysuru,

Karnataka, India

\section{Analysis of Tabebuia rosea oil and Tabebuia rosea oil methyl esters using Fourier transform infrared (FTIR) spectroscopy}

\section{Sindhuja Sirigeri and Belagali SL}

DOI: https://doi.org/10.22271/plants.2020.v8.i6a.1221

\section{Abstract}

Fourier transform infrared (FTIR) spectroscopy method was used for the analysis of phytochemicals present in Tabebuia rosea seed oil and its biodiesel. FT-IR spectra of Tabebuia rosea seed oil and its biodiesel have been recorded in the region $2925-604 \mathrm{Cm}^{-1}$. FT-IR is a vibrational spectroscopy that records absorptions of IR light by chemical bonds in all molecules including polymers. The different frequency ranges and their different functional groups were analyzed during the study period. FT-IR spectroscopy of the Tabebuia rosea seed oil reveals diverse functional groups and there by confirmed the possible presence of phytochemicals such as Terpenoids, Steriods, Flavonoids, Tannins, Coumarins, etc.

Keywords: Fourier transform infrared (FTIR) spectroscopy, Tabebuia rosea, botanical origin, biofuel

\section{Introduction}

FT-IR is one of the most extensively used methods to classify the chemical constituents and elucidate the compounds structures, and has been used as an essential method to identify medicines in Pharmacopoeia of many countries. Owing to the fingerprint characters and extensive applicability to the samples, FT-IR has played an important role in pharmaceutical analysis in recent years ${ }^{[1]}$.

Fourier transform infrared (FTIR) spectroscopy has received great attention in quantitative analysis of fats and oils over the years. It has a major advantage over the conventional grating instruments, having more energy throughput (the Jacquinot advantage), excellent reproducibility, and accuracy from the laser source. With increasing use of the microcomputer, FTIR is capable of manipulating spectral information (subtraction, rationing, derivative spectra, and deconvolution) and advanced chemometric software to handle calibration development ${ }^{[2]}$.

In the search for products derived from plants with potential biological activity, it has been described that some species belonging to the Bignoniaceae family have anti-inflammatory, anti-microbial, and anti-tumoral potential, due to its empirical use in rural areas in Colombia, Bolivia, Brazil, and other Latin American countries. Within this family, Tabebuia rosea (Bertol.) DC. Has been known to be used in traditional medicine in the Northern Coast of Colombia for the treatment of skin conditions such as pruritic diseases and infections with fungi and yeast.

T. rosea is a tree that reaches $30 \mathrm{~m}$ height and has a $1 \mathrm{~m}$ diameter trunk, its bark is flaky and is recognized by bell-shaped ornate purple and pink flowers3.Few studies have evaluated the biological activity of $T$. rosea extracts; therefore, the aim of this work was to determine the antioxidant, anti-inflammatory, and antiproliferative potential of the leaf and inner bark extracts obtained from $T$. rosea ${ }^{[3]}$. Based on the review of literature there is no study recorded in Tabebuia rosea. Hence, in the current study an attempt had been made to identify phytochemicals present in Tabebuia rosea seed oil and its biodiesel by FTIR methods.

\section{Methods and Materials}

The Tabebuia rosea seeds were collected and segregated from the campus of University of Mysore. The seeds were randomly selected according to the amount needed for the experimental work in the month of January and February. 
Prior to the extraction process, the seeds were dried at $60{ }^{\circ} \mathrm{C}$ for 7 hrs till weight remains constant, in order to reduce the moisture content. The separation of the outer cover from the seeds (cotyledon) was carried out by hand removal in order to achieve very high yield. Mortar and pestle were used to pulverise the seeds into coarse powder ${ }^{[4]}$.

\section{Extraction and conversion of oil}

The oil was extracted using Soxhlet extractor with Petroleum ether as the solvent at $40-60{ }^{\circ} \mathrm{C}$. This was allowed to continue for 2-3 hours. At the end of extraction, the resulting mixture containing the oil was heated to recover solvent from the oil. The experiment was repeated by placing fresh seed powder sample for further extraction of oil.

Conversion of the oil to biodiesel/TOME (T.rosea oil methyl esters) was carried out according S. Sirigeri et al. (2019) ${ }^{[5]}$.

\section{FT-IR analysis}

The FT-IR studies have been followed by the method described by Yang, $\mathrm{H}$ et al. (2005) ${ }^{[6]}$. The sample was completely dried to remove the solvent and the surface adhered film was scratched carefully and its FT IR spectra were recorded using a PerkinElmer (Instrument Serial Number 94012) double beam spectrometer in the spectral range of $4000-400 \mathrm{~cm}-1$. FT IR spectra were recorded to identify the functional groups of the extracted oil and TOME.

\section{Results}

\section{Analysis of the oil}

The obtained FT IR spectrum for the Tabebuia rosea seed oil to identify the functional groups is given below (figure. 01). The peaks obtained for the oil sample is given in the Table 1. The analytical evaluation of the oil was carried out by the comparison of the peaks with the previous similar works of Hong yang et al. (2005) ${ }^{[7]}$, Lerma-garcia et al. (2010) ${ }^{[8]}$ and Pugazhendy (2012) ${ }^{[9]}$. The analytical evaluation of the oil spectra is given in Table 02 .

\section{Analysis of the Biodiesel}

The obtained FT IR spectrum for the Tabebuia rosea oil methyl esters (TOME) to identify the functional groups is given below (figure. 02). The peaks obtained for the TOME is given in the Table 3 .

The analytical evaluation of the oil was carried out by the comparison of the peaks. The peaks observed were similar to that of the oil (table 2) with few other additional peaks which were classified to the functional groups as listed in the table 4 .

\section{Discussion}

FT-IR technique was used for evaluation the type of organic and inorganic complexes in plant extract. From the spectra (Fig. 1 and 2), we can see clearly that although they show substantial overlap of each absorption spectrum of various components, each band represents an overall overlap of some characteristic absorption peaks of functional groups in the samples. The FTIR spectra of Tabebuia rosea seed oil and its biodiesel are rather similar. The FT-IR analyzes of Tabebuia rosea seed oil and TOME represents the following functional groups. The infra-red spectrum shows a frequency ranges from 3000-2850 $\mathrm{cm}^{-1}$ peaks represent the C-H stretching vibration presence of alkenes ${ }^{[1]}$. The frequency ranges from 3300-2500 cm-1 peak display the characteristic absorptions of groups representing aliphatic $\mathrm{O}-\mathrm{H}$ stretching vibration which indicate the presence of carboxylic acids. The frequency ranges from 2260-2100 cm-1 peak correspond to $\mathrm{C}$ (triple bond) $\mathrm{C}-$ stretching vibration (ester alkynes) ${ }^{[10]}$. The frequency ranges from $1750-1735 \mathrm{~cm}^{-1}$ peak represent $\mathrm{C}=\mathrm{O}$ stretching vibration (ester and amino acid) ${ }^{[11]}$. The following peaks $1680-1640 \mathrm{~cm}-1$ are mainly attributed to the $-\mathrm{C}=\mathrm{C}-$ stretching vibration present in the alkenes. The frequency ranges from $1550-1475 \mathrm{~cm}^{-1}$ peak are assigned to the $\mathrm{N}-\mathrm{O}$ asymmetric stretching vibration present in the nitro compounds. The particular frequency ranges from 1320-1000 $\mathrm{cm}^{-1} \mathrm{C}-\mathrm{O}$ stretching, $\mathrm{O}-\mathrm{H}$ bending vibration indicate presence of alcohols, carboxylic acids, esters, ethers. The following frequency ranges from $1300-1150 \mathrm{~cm}^{-1}$, are assigned to the $\mathrm{C}-\mathrm{H}$ wag $(-\mathrm{CH} 2 \mathrm{X})$ stretching presence of alkyl halides, the peak range $1250-1020 \mathrm{~cm}^{-1}$ present in $\mathrm{C}-\mathrm{N}$ stretching, presence of aliphatic amines, the peak value representing 910-665 $\mathrm{cm}^{-1}$ appears in $\mathrm{N}-\mathrm{H}$ symmetric stretching vibration primary, secondary amines. The frequency ranges from 700$610 \mathrm{~cm}^{-1}$ peaks represent the $-\mathrm{C}$ (triple bond) $\mathrm{C}-\mathrm{H}$ : $\mathrm{C}-\mathrm{H}$ bend stretching vibration of alkynes components. The frequency ranges from $690-515 \mathrm{~cm}^{-1}$ peaks characterize $\mathrm{C}-\mathrm{Br}$ stretching vibration presence of alkyl halides compounds ${ }^{[10]}$. However, their tiny differences make it difficult to identify unambiguously them by utilizing the conventional FT-IR technique only. So, depending on the fingerprint characters of the peaks positions, shapes and intensities, the fundamental components indwell in the materials can been seen clearly ${ }^{[1]}$.

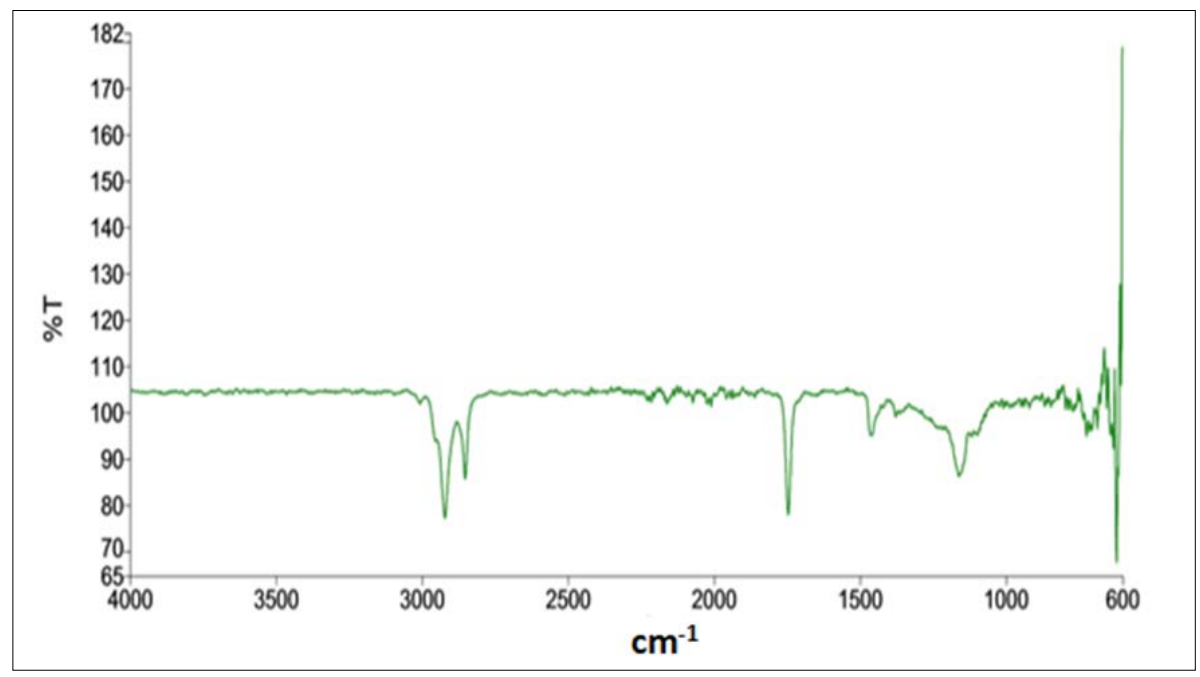

Fig 1: IR peaks of Tabebuia rosea seed oil 


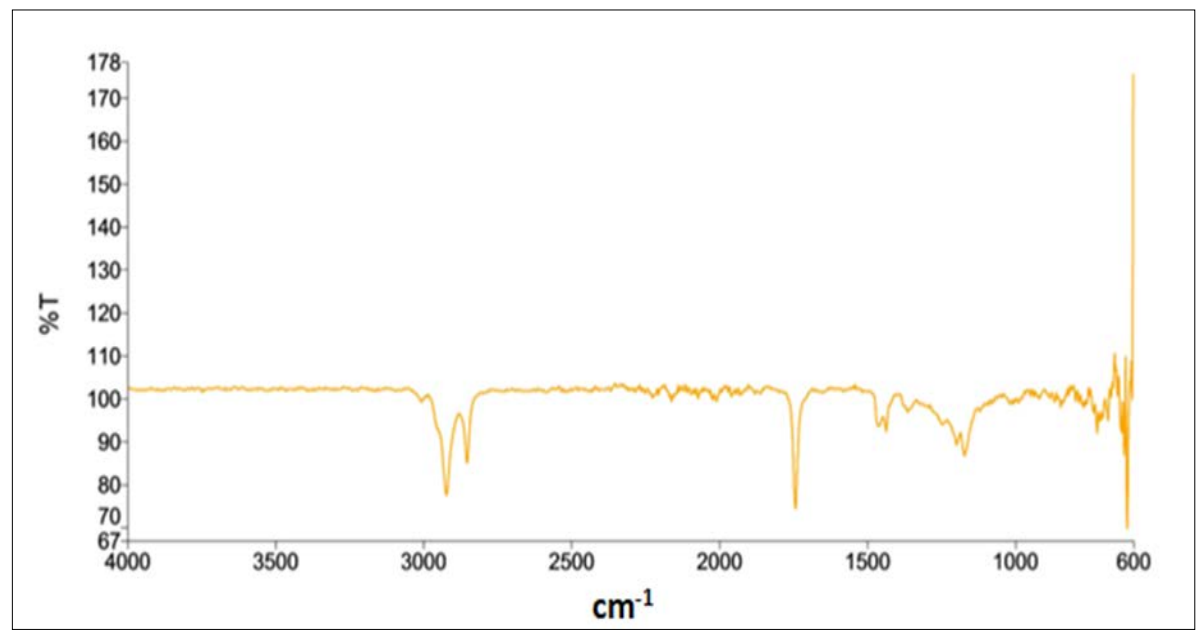

Fig 2: IR peaks of Tome

Table 1: IR peaks obtained for the oil sample

\begin{tabular}{|c|c|c|c|c|c|c|c|c|c|c|c|}
\hline Peak & $\mathbf{X}\left(\mathbf{c m}^{-\mathbf{1}}\right)$ & $\mathbf{Y}(\mathbf{\% T})$ & Peak & $\mathbf{X}\left(\mathbf{c m}^{-\mathbf{1}}\right)$ & $\mathbf{Y ( \% )}$ & Peak & $\mathbf{X}\left(\mathbf{c m}^{-\mathbf{1}}\right)$ & $\mathbf{Y ( \% T )}$ & Peak & $\mathbf{X}\left(\mathbf{c m}^{-\mathbf{1}}\right)$ & $\mathbf{Y}(\mathbf{\%} \mathbf{)})$ \\
\hline 1 & 2924.3 & 76.56 & 2 & 2854.48 & 84.6 & 3 & 2215.5 & 100.25 & 4 & 2162.53 & 99.91 \\
\hline 5 & 2073.14 & 100 & 6 & 2010.17 & 99.33 & 7 & 1958.53 & 100.88 & 8 & 1746 & 77.28 \\
\hline 9 & 1462.26 & 93.44 & 10 & 1377.58 & 97.25 & 11 & 1161.71 & 85.12 & 12 & 844.43 & 99.2 \\
\hline 13 & 794.11 & 98.8 & 14 & 782.91 & 98.64 & 15 & 768.42 & 98.39 & 16 & 722.2 & 93.35 \\
\hline 17 & 710.87 & 94.22 & 18 & 685.12 & 94.83 & 19 & 653.32 & 99.01 & 20 & 640.82 & 93.57 \\
\hline 21 & 629.61 & 90.71 & 22 & 619.41 & 67.58 & 23 & 603.44 & 103.61 & & & \\
\hline
\end{tabular}

Table 2: Assessment of spectral range of FT IR to functional groups of $T$. rosea Oil

\begin{tabular}{|c|c|c|}
\hline Sl. No & Range $\left.\mathbf{~ c m}^{-\mathbf{1}}\right)$ & Functional group \\
\hline 1. & $2946-2881$ & $-\mathrm{C}-\mathrm{H}_{(}\left(\mathrm{CH}_{2}\right)$ \\
\hline 2. & $2881-2782$ & $-\mathrm{C}-\mathrm{H}_{2}\left(\mathrm{CH}_{2}\right)$ \\
\hline 3. & $2260-2100$ & $-\mathrm{C}($ triple bond)C-, presence of alkynes \\
\hline 4. & $1795-1677$ & $-\mathrm{C}=\mathrm{O}(\mathrm{ester})$ \\
\hline 5. & $1486-1446$ & $-\mathrm{C}-\mathrm{H}\left(\mathrm{CH}_{2}\right)$ \\
\hline 6. & $1382-1371$ & $-\mathrm{C}-\mathrm{H}\left(\mathrm{CH}_{3}\right)$ \\
\hline 7. & $1211-1147$ & $-\mathrm{C}-\mathrm{O}$ \\
\hline 8. & $885-802$ & $=\mathrm{CH} 2$ \\
\hline 9. & $802-754$ & $-\mathrm{C}-\mathrm{H}$ \\
\hline 10. & $754-701$ & $-(\mathrm{CH})_{\mathrm{n}}-,-\mathrm{HC}=\mathrm{CH}-($ cis $)$ \\
\hline 11. & $700-610$ & $-\mathrm{C}($ triple bond $) \mathrm{C}-\mathrm{H}: \mathrm{C}-\mathrm{H}$, presence of alkynes \\
\hline 12. & 709 & $\mathrm{C}-\mathrm{H}$ \\
\hline 13. & $690-515$ & $\mathrm{C}-\mathrm{Br}, \mathrm{presence} \mathrm{of} \mathrm{alkyl} \mathrm{halides}$ \\
\hline
\end{tabular}

Table 3: IR peaks obtained for the TOME sample

\begin{tabular}{|c|c|c|c|c|c|c|c|c|c|c|c|}
\hline Peak & $\mathbf{X}\left(\mathbf{c m}^{-\mathbf{1}}\right)$ & $\mathbf{Y ( \% )}$ & Peak & $\mathbf{X}\left(\mathbf{c m}^{-1}\right)$ & $\mathbf{Y ( \% T )}$ & Peak & $\mathbf{X}\left(\mathbf{c m}^{-\mathbf{1}}\right)$ & $\mathbf{Y ( \% T )}$ & Peak & $\mathbf{X}\left(\mathbf{c m}^{-\mathbf{1}}\right)$ & $\mathbf{Y}(\mathbf{\%})$ \\
\hline 1 & 2924.58 & 77.4 & 2 & 2854.47 & 85.03 & 3 & 2226.96 & 100.2 & 4 & 21.62 .56 & 99.44 \\
\hline 5 & 2072.65 & 100.08 & 6 & 2009.75 & 99.4 & 7 & 1959.59 & 100.52 & 8 & 742.85 & 74.32 \\
\hline 9 & 1462.5 & 93.59 & 10 & 1435.93 & 92.41 & 11 & 1363.47 & 96.86 & 12 & 1197.81 & 89.23 \\
\hline 13 & 1171.03 & 86.68 & 14 & 1007.23 & 98.64 & 15 & 918.77 & 100.02 & 16 & 865.81 & 99.21 \\
\hline 17 & 844.89 & 98.05 & 18 & 794.23 & 99.42 & 19 & 768.11 & 97.93 & 20 & 721.87 & 92.06 \\
\hline 21 & 711 & 94.75 & 22 & 685.12 & 94.95 & 23 & 653.27 & 100.7 & 24 & 639.05 & 92.12 \\
\hline 25 & 630.4 & 86.93 & 26 & 620.43 & 69.6 & 27 & 603.57 & 99.79 & & & \\
\hline
\end{tabular}

Table 4: Assessment of spectral range of FT IR to functional groups of TOME

\begin{tabular}{|c|c|c|}
\hline Sl. No & Range $\left(\mathbf{~ m}^{-\mathbf{1}}\right)$ & Functional group \\
\hline 1. & $1446-1425$ & $-\mathrm{C}-\mathrm{H}\left(\mathrm{CH}_{3}\right)$ \\
\hline 2. & $1043-1006$ & $-\mathrm{C}-\mathrm{O}$ \\
\hline 3. & $929-885$ & $-\mathrm{HC}=\mathrm{CH}-$ (cis) \\
\hline
\end{tabular}

\section{Conclusion}

Based on the systematically analysis of Tabebuia rosea seed oil and Tabebuia rosea oil methyl esters (TOME) contains important phytochemicals like reducing sugar, flavonoids, glycosides, tannins and terpenoid, which may contribute to its biological activities. The present results clearly indicate that
Tabebuia rosea seed extracts possess significant phenolic acids and therefore capable of antioxidant activities like synthetic drug ascorbate. FT-IR spectroscopy of the Tabebuia rosea seed oil reveals diverse functional groups and there by confirm the possible potential antioxidant activity and free radical scavenging properties.

\section{References}

1. Liu HX, Sun SQ, Lv GH, Chan KK. Study on Angelica and its different extracts by Fourier transform infrared spectroscopy and two-dimensional correlation IR spectroscopy. Spectrochimica Acta Part A: Molecular and Biomolecular Spectroscopy 2006;64(2):321-326. 
2. Che Man YB, Moh MH, Van de Voort FR. Determination of free fatty acids in crude palm oil and refined-bleached-deodorized palm olein using fourier transform infrared spectroscopy. Journal of the American Oil Chemists' Society 1999;76(4):485-490.

3. Jimenez-Gonzalez FJ, Vélez-Gómez JM, MelchorMoncada JJ, Veloza LA, Sepúlveda-Arias JC. Antioxidant, anti-inflammatory, and antiproliferative activity of extracts obtained from Tabebuia Rosea (Bertol.) DC. Pharmacognosy Magazine 2018;14(55):25.

4. Sobiyana P, Anburaj G, Manikandan R. Antioxidant and Antimicrobial Activities of Tabebuia Rosea. International journal of Nano corrosion science and engineering 2015;2(6):24-30.

5. Sirigeri S, Vadiraj KT, Belagali SL. Tabebuia rosea: a prospective non-edible biodiesel feedstock. Biofuels 2019, 1-3.

6. Yang $\mathrm{H}$, Irudayaraj J, Paradkar MM. Discriminant analysis of edible oils and fats by FTIR, FT-NIR and FTRaman spectroscopy. Food Chemistry 2005;93(1):25-32.

7. Yang $\mathrm{H}$, Irudayaraj J, Paradkar MM. Discriminant analysis of edible oils and fats by FTIR, FT-NIR and FTRaman spectroscopy. Food Chemistry 2005;93(1):25-32.

8. Lerma-García MJ, Ramis-Ramos G, Herrero-Martínez JM, Simó-Alfonso EF. Authentication of extra virgin olive oils by Fourier-transform infrared spectroscopy. Food Chemistry 2010;118(1):78-83.

9. Pugazhendy K. Fourier Transform Infrared FT-IR Spectoroscopic Analysis of Spirulina. International Journal of Pharmaceutical \& Biological Archive 2012, 3(4).

10. Theivandran G, Ibrahim SM, Murugan M. Fourier Transform Infrared (Ft-Ir) Spectroscopic Analysis of Spirulina Fusiformis. Journal of Medicinal Plants Studies 2015;3(4):30-32.

11. Venkatesan S, Pugazhendy K, Sangeetha D, Vasantharaja C, Prabakaran S, Meenambal M. Fourier transform infrared (FT-IR) spectoroscopic analysis of Spirulina. International Journal of Pharmaceutical \& Biological Archives 2012;3(4):969-972. 